
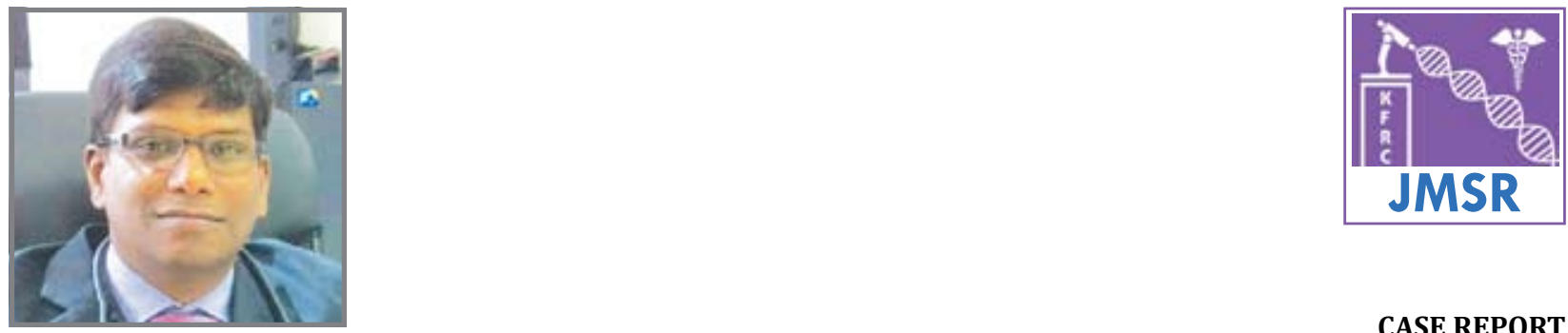

Dr. Srinivas Bacchu

CASE REPORT

\title{
Plasma cell dyscrasia presenting as retro-orbital mass - lessons to learn?
}

\author{
Dr. Srinivas Bacchu1 ${ }^{1, *}$ and Dr. VS. Reddy ${ }^{2}$ \\ ${ }^{1}$ Consultant Haematologist \& Bone marrow transplant specialist, Krishna Institute of Medical Sciences, \\ Minister Road, Secunderabad-500003, Telangana, India \\ 2 Department of Nephrology, Krishna Institute of Medical Sciences, Minister Road, Secunderabad-500003, Telangana, India
}

\begin{abstract}
A patient with myeloma presenting as retro orbital mass and renal failure is described. Myeloma patients can present to any physician with any specialty. Renal impairment is quite common in myeloma. Early recognition of this complication is important in preserving the kidneys. The patient was treated with Bortezomib and Dexamethasone and had good initial response to treatment.
\end{abstract}

Keywords: Plasma cell dyscrasia; retro-orbital mass; Bortezomib; Dexamethasone

*Corresponding author: Dr Srinivas Bacchu, MBBS, MD, MRCP, FRC Path (Haematology), Fellowship in Bone Marrow Transplantation (Bristol, UK), Consultant Haematologist, Haemato-Oncologist, Bone marrow transplant specialist, Krishna Institute of Medical Sciences, Minister Road, Secunderabad500003, Telangana, India, Tel +914044885197; E- mail: srinivas. bacchu@gmail.com

Received 19 April 2014; Revised 16 May 2014; Accepted 2 June 2014

Citation: Srinivas Bacchu, Reddy VS (2014) Plasma cell dyscrasia presenting as retro-orbital mass - lessons to learn? J Med Sci Res 2(3):158-160. DOI: http://dx.doi.org/10.17727/JMSR.2014/2029

Copyright: () 2014 KIMS Foundation and Research Centre. All Rights Reserved.

\section{Case presentation}

A 68 year-old man presented to hospital with history of decreased vision in his right eye for the last three months, associated with ptosis and proptosis, which was gradual in onset. For the last fifteen days he was suffering from headache which was diffuse and throbbing in nature. He was admitted for further evaluation under neurosurgical team. His vision was noticed to be reduced to finger counting at one meter distance and his pupillary reaction was sluggish. He also complained of left arm pain for a month.

Clinical examination revealed complete third, fourth, sixth and partial second nerve palsy on the right side with proptosis. His left arm had restricted movements and there was local tenderness below his shoulder joint.

Surgical intervention was planned.Hispreanaesthetic evaluation revealed an $\mathrm{Hb} 10.7 \mathrm{gms} / \mathrm{dl}$, White blood cells 6900 cells/cumm, platelets 2.08 lakhs/cumm, creatinine $4.9 \mathrm{mg} / \mathrm{dl}$, potassium $4.9 \mathrm{mmol} / \mathrm{dl}$. In view of raised creatinine, surgical evaluation was postponed and renal work up was done. This revealed 
absence of Bence-Jones protein, no abnormal $\mathrm{M}$ band but an abnormal serum free light chain ratio (SFLC) ratio. Kidneys were of normal size.

In view of normal sized kidneys, with no apparent cause for renal failure investigation for myeloma was taken up in view of abnormal SFLC. He underwent a bone marrow biopsy which confirmed a diagnosis of myeloma. In light of this, no further surgical intervention was done for his right retrobulbar mass (plasmacytoma) and renal biopsy was avoided as well. A skeletal survey revealed a plasmacytoma in the rib (Figure 1) and lytic lesion in his left humerus (Figure 2). CT scan showed ethmoidal mass on right side (Figure 3). PET scan showed additional lesions in his sternum (Figure 4) and sacrum bone (Figure 5) causing line of symptoms.

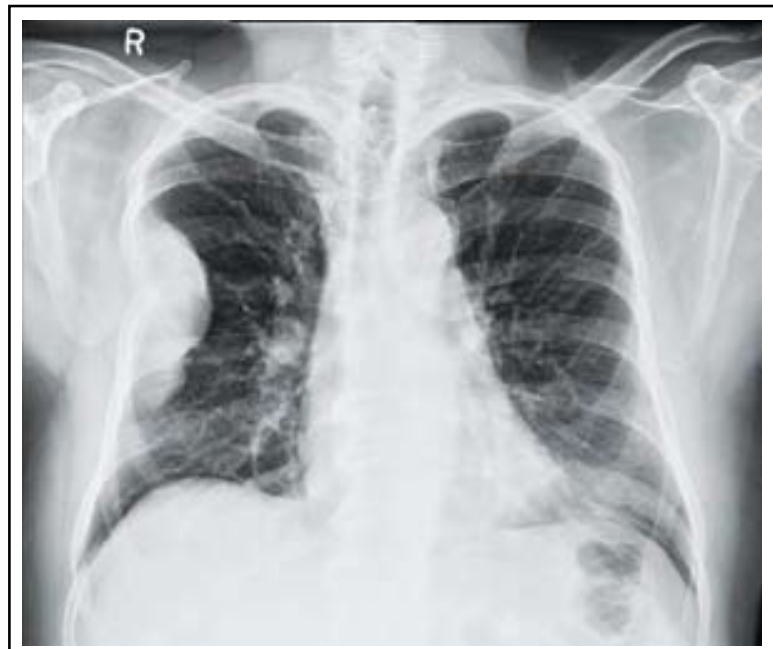

Figure 1: Chest radiography extrapleural mass due to myeloma of the rib.

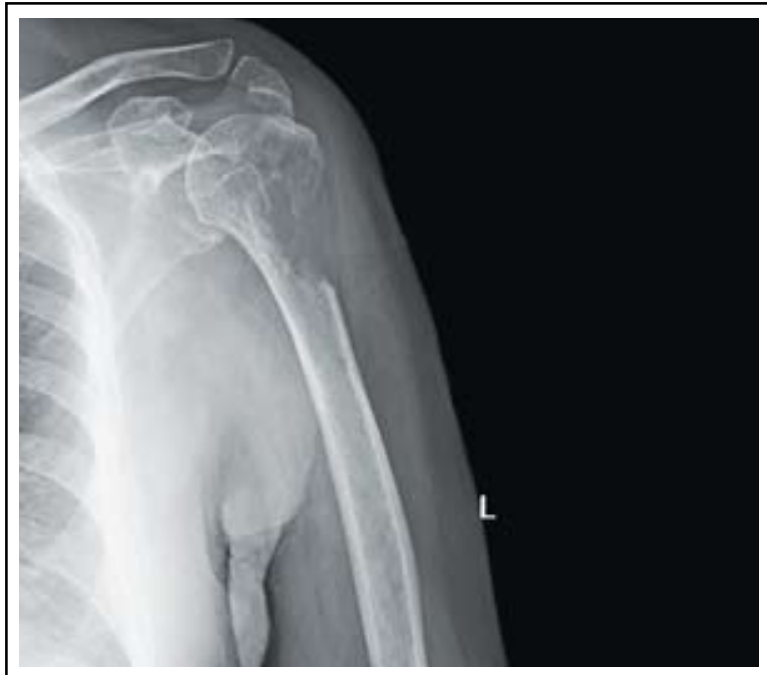

Figure 2: Large lytic lesion in proximal humerus.

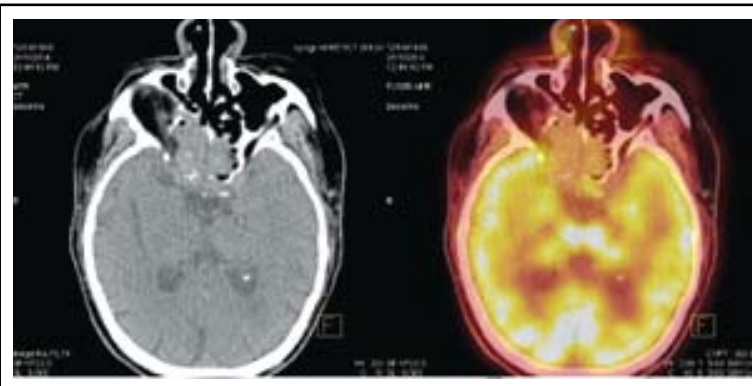

Figure 3: CT scan shows ethmoidal mass on right side.

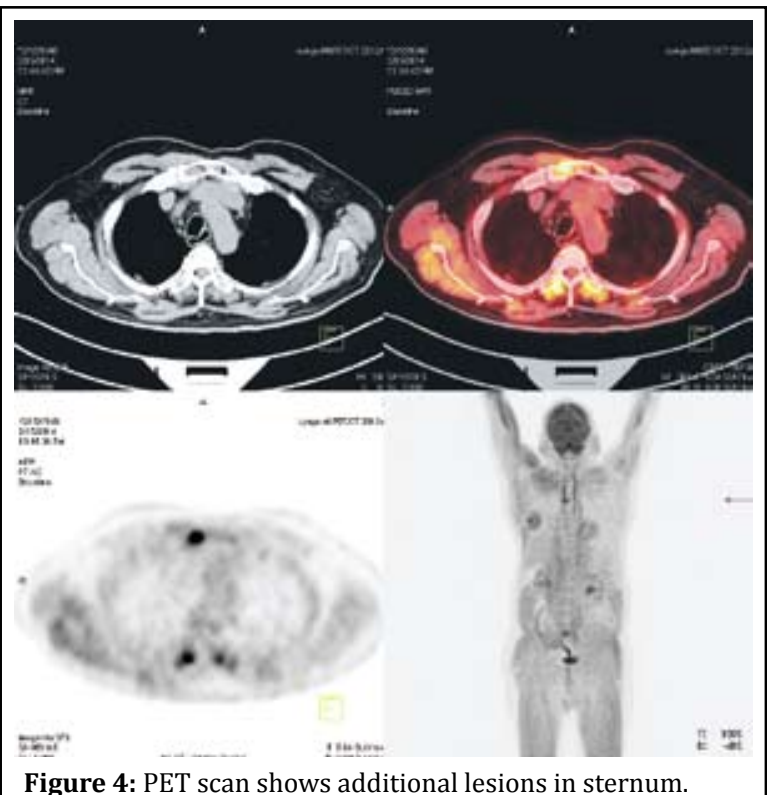

Figure 4: PET scan shows additional lesions in sternum.

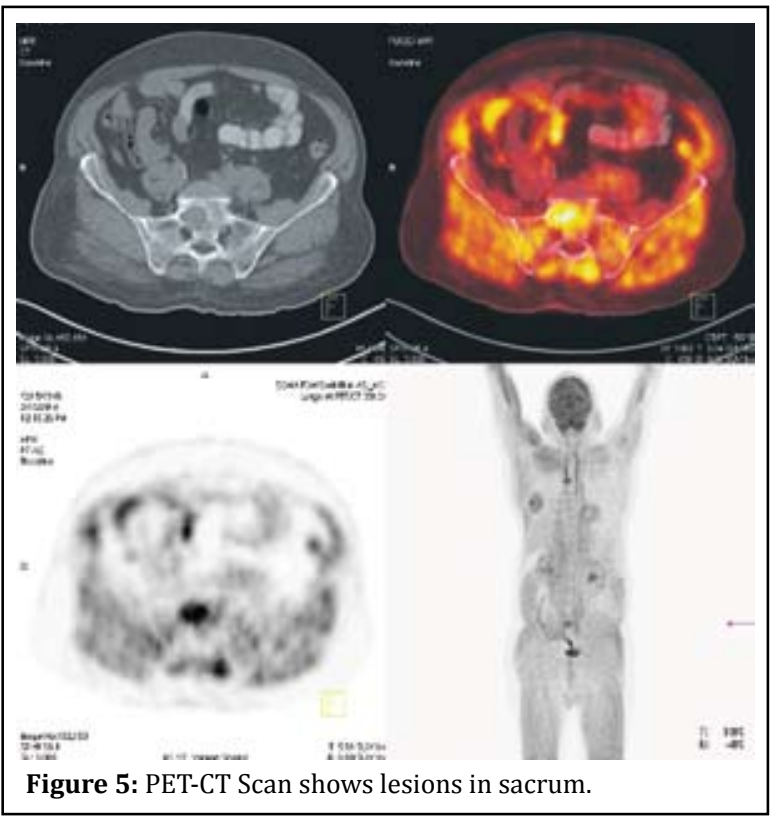

\section{Clinical course}

He was vigorously hydrated. Initial treatment was with Dexamethasone and Bortezomib and within 
a week his creatinine improved to $1.5 \mathrm{mg} / \mathrm{dl}$. His headache and ptosis have improved. However, due to funding issues he was unable to receive prophylactic nailing of his humerus which resulted in facture at the end of his first cycle of treatment.

\section{Discussion}

Myeloma has a higher incidence in African population followed by Caucasian population. Its incidence in South East Asia comparatively is less [1]. Incidence increases with age and peaks 6 to 7 th decade. Younger patients aged less than $40 \mathrm{yrs}$ tend to have aggressive disease.

Principal laboratory features are stands for raised calcium, renal failure, anaemia and lytic bone lesions (CRAB). However, they can present with hypercalcemia, infections and rarely with hyperviscosity.

The incidence of renal disease in myeloma is about $25-50 \%$ [2] and 2- $12 \%$ [3] patients may end up on dialysis. It is quite important that myeloma patients with renal dysfunction are identified early, as this group generally does not do as well as compared with those without. Around 30\% with renal failure die within 60 days [4] and the cause of early mortality is renal failure with infection. It is important that attention is given to adequate hydration and to avoid nephrotoxic drugs. It is known that rapid institution of anti-myeloma treatment can salvage kidneys. Either high dose Dexamethsone or its combination with more definitive treatment such as Bortezomib can be used.

Bence Jones proteins test is easy and inexpensive method for testing light chain and 5 to $10 \%$ of the myeloma patients will have light chines only (Bence Jones protein) and should be undertaken in all cases of suspected Myeloma. However in this patient this was negative. Light chain disease is the main cause of renal failure in myeloma. SFLC chain assay is a difficult test to standardize and is often abnormal in renal failure due to other causes, making this difficult test to interpret. One important thing to notice is the kappa/ lamda ratio would be within normal range in renal failure due to other causes. It is always important to interpret results in the context of clinical setting.

Multiple plasmacytomas, irrespective of plasma cell load burden in the marrow, are treated as Myeloma [5]. It is always important in suspected solitary plasmacytoma to investigate by bone marrow test, and PET-CT scan looking for any other asymptomatic ones, as principal treatment modality and prognosis are different. PET-CT is reliable to assess disease burden and treatment response. Radiotherapy is an important tool in treatment of plasmacytomas which are causing pain or functional impairment but need to be considered after surgical fixation if bone is at risk for pathological facture as in this patient.

\section{Conclusion}

Myeloma is treatable disease; median survival has improved over the last decade and is around 6-7 yrs. There are many novel therapeutic agents which are available and changed the way we treat this disease. Myeloma patients can present to any department and it is important to identify these patients. Renal impairment is an important complication and can be reversed if identified early and treated. Bortezomib is an important drug in management of myeloma with renal failure as this acts quite quickly and known to work synergistically with Dexamethasone. This was a complicated case, and highlights multidisciplinary approach to improve patient outcomes.

\section{Acknowledgements}

Acknowledgements are due to Department of Radiology and Imaging, KIMS, Secunderabad, Telangana, India.

\section{Conflict of interest}

The author declares no conflict of interest.

\section{References}

1. SEER 18 2006-2010, National cancer institute.

2. Knuden LM, Hipp E, Hjorth M, Holmberg E, Westin J. Renal function in newly diagnosed multiple myeloma- a demographic study of 1353 patients. The Nordic myeloma Study group. European Journal of Haematology 1994; 53:207-212.

3. Clark AD, Shetty A, Soutar R. Renal failure and multiple myeloma: pathogenesis and treatment of renal failure and management of underlying myeloma. Blood Reviews 1999; 13:79-90.

4. Auguston BM, Begum G, Dunn JA, Barth NJ, Davies F, et al. Early mortality after diagnosis of multiple myeloma: analysis of patients entered onto the United kingdom Medical Research council trials between 1980 and 2002-Medical Research Council Adult Leukemia Working Party. Journal of Clinical Oncology 2005; 23:9219-9226.

5. UK Myeloma Forum and the Nordic study group: Guidelines on the diagnosis and management of multiple myeloma. British Journal of Haematology 2005; 132:410-451. 